\title{
EARTH-POTENTIAL ELECTRODES IN PERMAFROST AND TUNDRA
}

\author{
V. P. Hessler and A. R. Franzke*
}

\section{Introduction}

D URING the past two years the authors installed a number of electrodes in the permafrost and tundra area of Point Barrow to obtain earthpotential data. An earth-potential recording installation consists of a pair of electrodes buried in the ground at a spacing of several hundred feet and connected to a recording millivoltmeter located at some central or convenient location. The instrument records the potential difference variations that appear between the electrodes due to motion of charges in the ionosphere. The data are correlated with other manifestations of ionospheric activity such as magnetic disturbances and the aurora. Thus earth-potential studies constitute an important technique in the general study of the ionosphere.

The resistances of the first set of electrodes increased by several orders of magnitude as ground temperatures dropped during the winter and thus the installation became useless. A second set of electrodes, with sodium chloride incorporated in the fill, proved entirely practical for recording earth potentials. The installations and procedure for determining electrode resistance are described. Data on electrode resistance plotted against time and ground temperature are also given.

\section{The untreated electrodes}

The first set of five electrodes was laid out as shown in Fig. 1. The X electrode was installed to give a pair in the geomagnetic meridian, and East was added because of unsatisfactory soil conditions at West electrode. Although the tundra area selected appears quite uniform, the soil at North, South, and X electrodes is clayey, at West electrode it is peat, and at East it is a soil-peat mixture.

The electrodes are lead sheets, 8 feet by 8 inches, cut into inch-wide strips, spread in a crowfoot pattern, and installed in a 6- by 6-foot excavation down to permafrost (Fig. 2). The average depth to permafrost in August 1955 was 12 inches. The excavated material was tamped in carefully around the electrode and then overlaid with sections of tundra vegetation to approximate the undisturbed conditions of the area. Lines were extended from each electrode to a small building that housed the recording equipment.

\footnotetext{
* Geophysical Institute of the University of Alaska.
} 


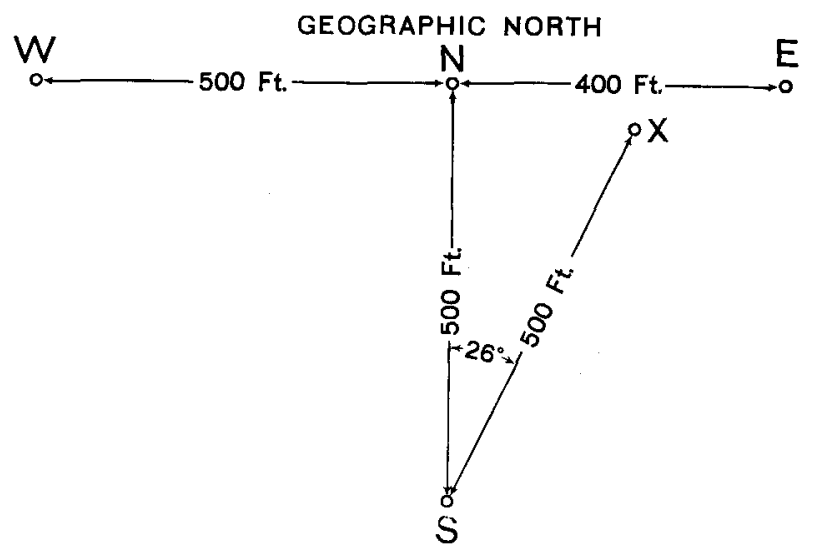

Fig. 1. Layout of untreated electrode set.

\section{Electrode-resistance measurements}

All electrode-resistance measurements were made with an ohmmeter of the type used in electronic circuit testing. Electrode pairs were connected to the ohmmeter and readings taken quickly to minimize the effect of polarization. Direct and reversed readings were taken to compensate for the error caused by chemical potential between the electrodes. The average of the two readings, which sometimes differed by as much as 5 per cent, was used to calculate the individual electrode-resistance. The ohmmeter gave resistance values that were sometimes too high, as was indicated by experience with a low-range Megger Ground-Tester that uses an a-c. source and thus eliminates errors due to polarization. However, acquisition of more accurate equipment for measuring resistances would not have been justified because knowledge of the electrode-resistance values was not required for the calibration of the earth-potential equipment.

Resistance readings were taken at frequent intervals between every possible electrode pair and individual electrode-resistance values were calculated from sets of three readings using the following equations:

$$
\begin{aligned}
& R_{1}=0.5\left(R_{12}+R_{13}-R_{23}\right) \\
& R_{2}=0.5\left(R_{23}+R_{21}-R_{31}\right) \\
& R_{3}=0.5\left(R_{31}+R_{32}-R_{12}\right)
\end{aligned}
$$

The subscripts 1,2, and 3, may stand for any three of the five electrodes. As a check, the resistance of, say $N$, was calculated in terms of $N, S$, and $W$ data and again in terms of $\mathrm{N}, \mathrm{E}$, and $\mathrm{X}$ data. All resistance values presented for the untreated electrodes are averages of two or more such calculations.

\section{Ground-temperature data}

Ground-temperature data were supplied by the U.S. Weather Bureau, Barrow Station. The temperature-sensitive devices are thermistors installed at various depths in the quadrangle of the station. The site of the untreated electrode group is in open country about 1 mile from the weather station. 


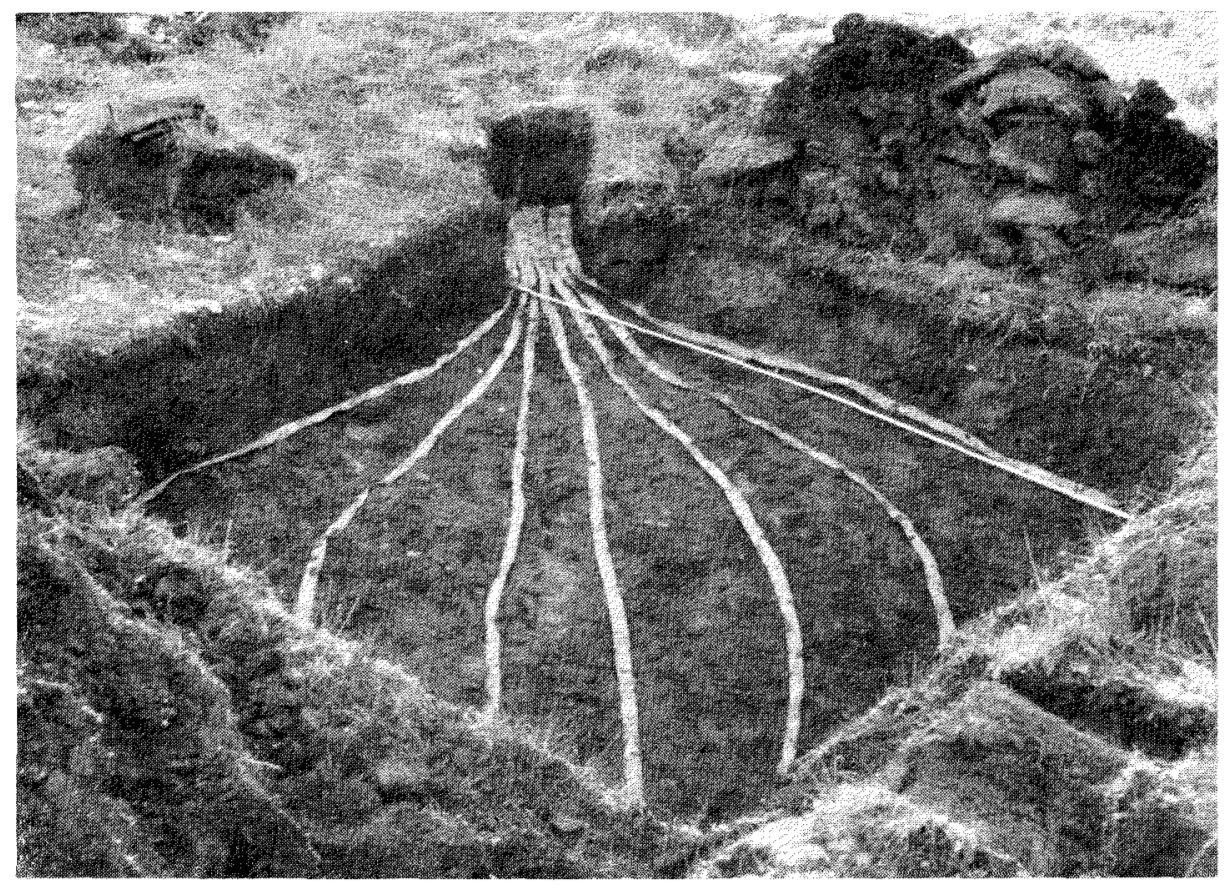

Fig. 2. Form of untreated electrode.

Thus it is probable that the recorded temperatures to a depth of a few feet may vary somewhat from the actual values at the electrodes, particularly during rapid air-temperature changes because of differences in the snow and vegetation cover. Reliable ground-temperature data for SeptemberDecember 1955 are unavailable because of instrumentation difficulties.

\section{Resistance data for untreated electrodes}

Resistance and temperature data for some of the untreated electrodes are presented in Figs. 3 and 4. The resistance-time curves for all 5 electrodes show the same general form. The resistance values of the $\mathrm{X}$ electrode lie between those of the $\mathrm{N}$ and $\mathrm{S}$ electrodes and the resistance values of the $\mathrm{E}$ and $\mathrm{W}$ electrodes are very much higher. The $\mathrm{W}, \mathrm{E}$, and $\mathrm{X}$ electrodes attained their maximum resistance values of 194,000, 141,000, and 36,200 ohms, respectively on March 4, 1956. The electrode resistance dropped to a minimum on August 19, 1956 with values ranging from 83 to 397 ohms. These minimum values are essentially the same as the values at the time of installation in late August 1955.

The four temperature curves of Fig. 3 are for ground surface and depths of 4,11 , and 22 feet. The temperature at 1 foot was practically the same as the surface-temperature. A maximum difference of $2.4^{\circ}$ occurred during a period of rapid temperature change. The close correlation between the 

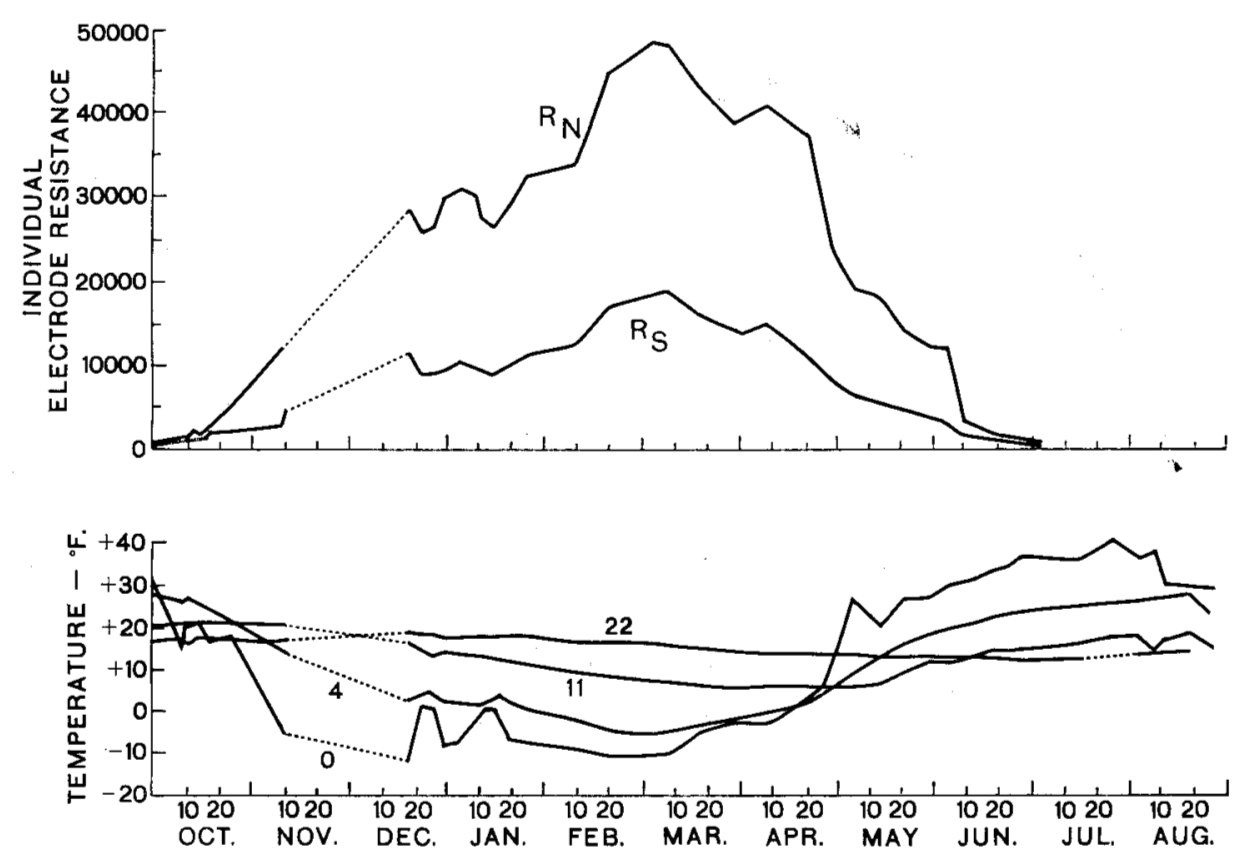

Fig. 3. Resistance and temperature data for untreated electrodes, Oct. 1956 to May 1957.

electrode-resistance and the temperatures near the ground surface is evident in Fig. 3 and appears throughout the more extensive data from which the curves were prepared.

The resistance-temperature relation is also exemplified by the resistance versus temperature locus of Fig. 4 . The hysteresis effect may be due to temperature time lag at the greater depths. The series of reversals on the ascending curve corresponds to the December-January data of Fig. 3. It should be noted that the major increase in resistance occurred as the ground temperature at the electrode decreased from $0^{\circ} \mathrm{F}$. to $-12^{\circ} \mathrm{F}$.

The winter electrode-resistance values are far too high for satisfactory earth-potential recording with most recording potentiometers. They are also too high to permit the use of transistor amplifiers that have inherently low input impedance. Vacuum-tube amplifiers overcome the input-impedance problem, but introduce the difficult problem of stability, particularly under field conditions. Thus it was essential to decrease the electrode resistance, if possible.

This could be done by increasing the size of the electrodes. Theoretical considerations show that the resistance of a hemispherical shell electrode, installed with its plane surface at ground level in homogeneous soil, varies inversely with the radius. Applying this relation as a rough approximation to the square outline of the electrodes indicates that the 6- by 6-foot size would have to be increased to a size of 30 by 30 feet to reduce the resistance to 20 per cent of the observed values. This would result in usable values 
Fig. 4.

Resistancetemperature relation for untreated south electrode.

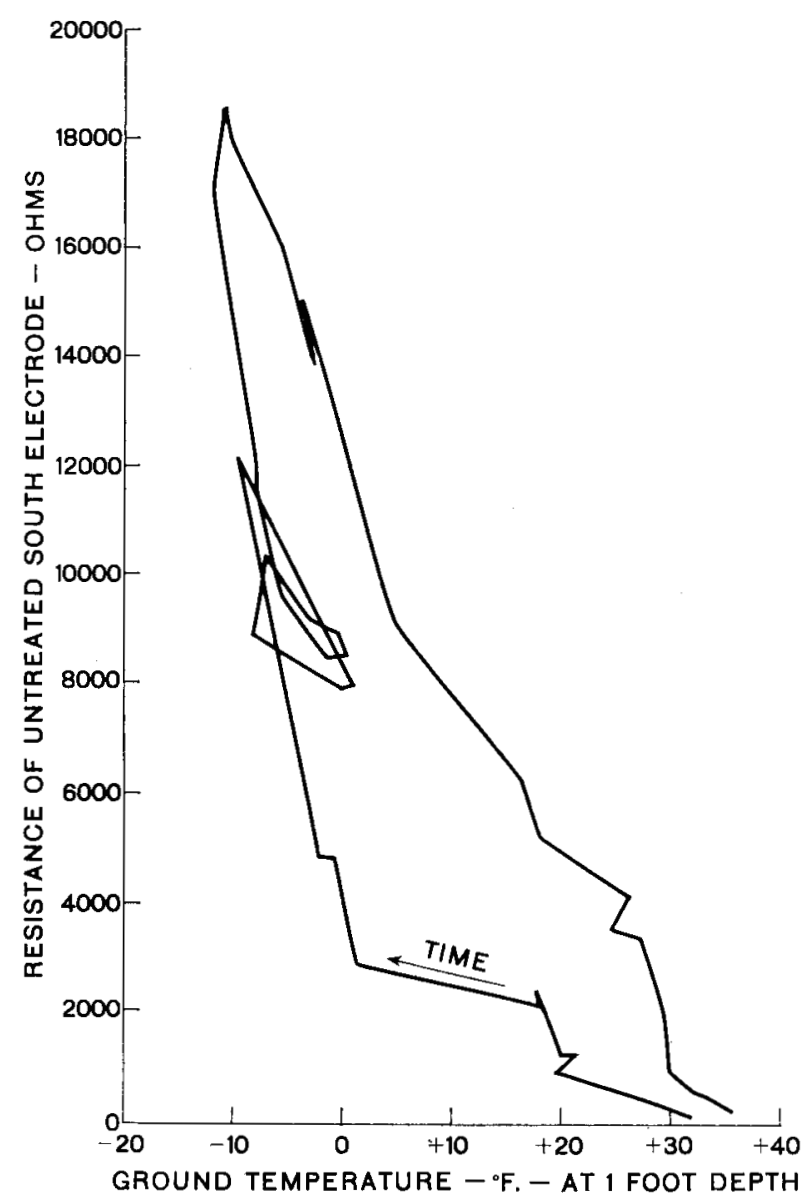

for the $N, S$, and $X$ electrodes, but not for the very high resistances of the $\mathrm{E}$ and $\mathrm{W}$ electrodes. Obviously, this solution of the problem is impractical.

The effect of the high electrode resistance could be reduced somewhat by increasing the electrode spacing because the magnitude of the earthpotential voltage is directly proportional to the electrode spacing, whereas the electrode resistance is essentially independent of spacing. However, the increased space and line wires required rules this out as a practical solution of the problem.

Therefore, the only practical procedure for reducing the electrode resistance seemed to be a moderate increase in electrode dimensions and treatment of the fill soil with sodium chloride. Chemical treatment of the fill soil had been avoided previously because of the possibility of introducing variable chemical potentials between electrode pairs.

\section{The treated electrodes}

During the summer of 1956 a second set of electrodes was installed in similar terrain and soil about 4 miles from the first set. For the common 


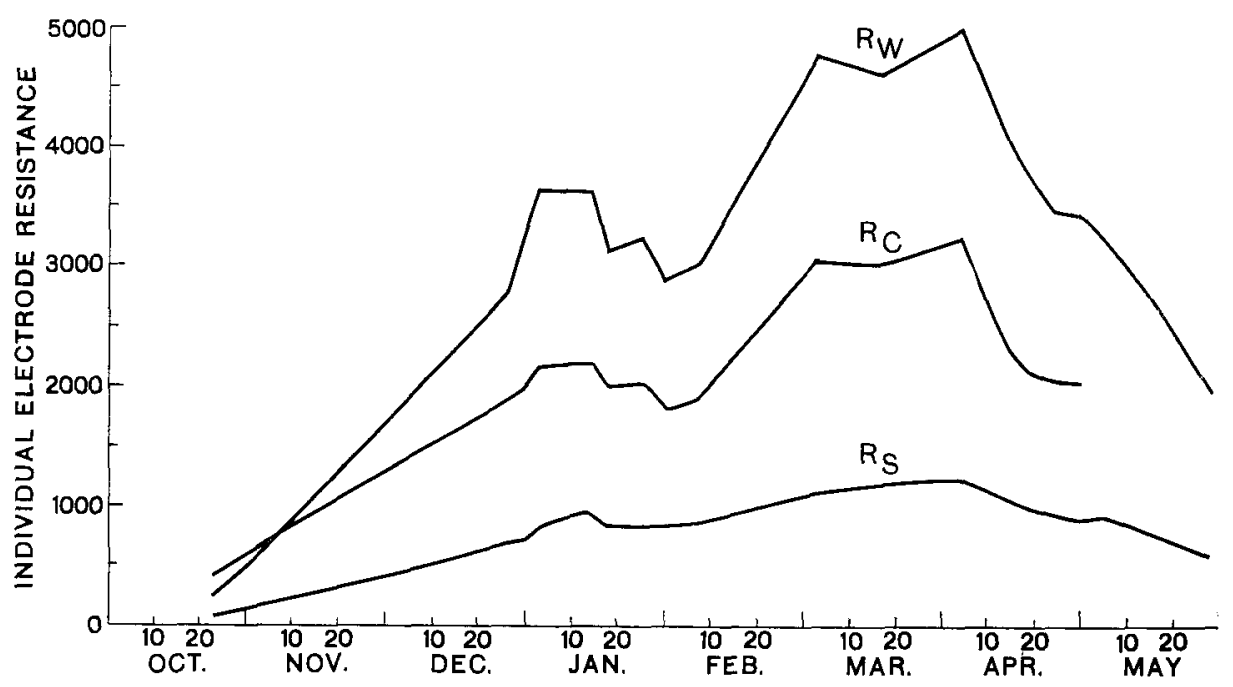

Fig. 5. Resistance of treated electrodes, Oct. 1956 to May 1957.

electrode two concentric circular trenches, 8 feet and 16 feet in diameter and 8 inches wide were excavated to permafrost, which was at a depth of 8 inches. A 50-foot length of 4-inch wide lead strip was placed in the bottom of the outer trench and tamped carefully with sodium chloride-treated soil. A 25-foot lead strip was placed in the bottom of the inner trench and covered to a depth of 4 inches. A second strip was then placed above the first and the fill was completed. One hundred pounds of sodium chloride were incorporated in the fill. Individual lines were extended from the two inner and the outer lead strips to the recording equipment. The West electrode installation is identical with the common electrode.

The South electrode is located at an old beach head, where it was impractical to use the form of the common and West electrodes. There a lead strip about 24 feet long was installed in a trench 12 feet long, 18 inches wide and 24 inches deep and tamped in carefully with the addition of about 50 pounds of sodium chloride to the fill. The spacings between the common and South, and the common and West electrodes are each 1,000 feet.

\section{Resistance data for the treated electrodes}

The individual resistances for the treated electrodes during the period October 1956 to May 1957 are shown in Fig. 5. $R_{c}$ and $R_{w}$ are the resistance values for the three lead strips of each of these electrodes connected in parallel. The May values of $R_{c}$ are omitted because the line to the outer loop of the electrode was broken.

The resistance of these electrodes is entirely satisfactory for recording earth-potentials even with the comparatively low input impedance transistor 
amplifiers. The low resistance can be definitely attributed to the nature of the installation, because the resistance of the untreated electrodes increased to values corresponding to those of the previous winter.

Much lower resistances than the winter values of these electrodes are desirable for other applications. How should the installation be modified to reduce the resistance further? The resistances of the lines and the electrode material are negligible. Thus, the only possibility of further reduction lies in reducing the contact resistance between metal and soil and the resistance of the ground. It is known that the contact resistance between metal and soil of the treated electrodes is also negligible. The resistance between the two inner lead strips of the West electrode was measured regularly during the test period and it never exceeded $20 \mathrm{ohms}$. The authors are confident that this low value of resistance is not due to an inadvertent metal to metal contact. A uniform layer of about 4 inches of sodium chloride-impregnated soil was tamped over the lower strip before installing the upper and completing the fill. Furthermore, the highest values of the resistance between the upper and lower strips coincided with the lowest temperatures. A continuous metal circuit would have shown the opposite temperature relation.

Apparently, the resistance of the treated electrodes is due almost entirely to the high resistance of the untreated soil. This suggests treating a considerable volume of soil around the electrode material as an economical means of further reducing the electrode resistance.

\section{Summary}

Untreated electrodes are impractical for earth-potential recording during the winter months in a tundra and permafrost region such as at Point Barrow. There is a close correlation between ground temperatures, to a depth of a few feet, and electrode resistance. A pronounced increase in resistance occurs at temperatures below $0^{\circ} \mathrm{F}$.

Electrodes treated with sodium chloride show resistances that are satisfactory for the recording of earth-potentials. Resistances of less than 5,000 ohms can be maintained during the winter with a relatively inexpensive electrode installation.

\section{Acknowledgements}

The authors wish to express their appreciation to the Arctic Institute of North America and the Office of Naval Research for the grant (Contracts Nos. ONR-161 and 188) in support for this study; to the Arctic Research Laboratory for logistic support and laboratory facilities; and to the U.S. Weather Bureau for supplying the ground-temperature data. 